\title{
Commitment and Sacrifice in Emerging Adult Romantic Relationships
}

\author{
J. KALE MONK \\ Department of Human and Community Development, University of Illinois at \\ Urbana-Champaign, Urbana, Illinois, USA
}

AMBER V. VENNUM

School of Family Studies and Human Services, Kansas State University, Manhattan, Kansas, USA

\section{BRIAN G. OGOLSKY}

Department of Human and Community Development, University of Illinois at Urbana-Champaign, Urbana, Illinois, USA

FRANK D. FINCHAM

FSU Family Institute, The Florida State University, Tallahassee, Florida, USA

The development of commitment and satisfaction with sacrifice has been associated with relationship health and stability. Given the importance of early romantic relationships, the purpose of the present study was to explore how these constructs relate and develop in an emerging adult population $(n=246)$. Through an initial confirmatory factor analysis, we found the two constructs can be distinct. Then, using interdependence theory and a cross-lagged model over three time points, we found support for a bidirectional relationship between commitment and satisfaction with sacrifice. In addition, we found a main effect for relationship length and instability (i.e., cycling) on Time 1 and Time 3 dedication respectively.

KEYWORDS commitment, dating relationships, early adulthood, interdependence

Address correspondence to J. Kale Monk, Department of Human and Community Development, 1105 W. Nevada Street, University of Illinois at Urbana-Champaign, Urbana, IL 61801, USA. E-mail: jkmonk@illinois.edu 


\section{INTRODUCTION}

Research suggests that early romantic relationships can foreshadow future adult relationship outcomes (Donnellan, Larsen-Rife, \& Conger, 2005). For example, low-quality romantic relationships in young adulthood have not only been found to be predictive of higher reports of mental health concerns like anxiety and depressive symptoms, but these relationships were also found to be predictive of low-quality relationships in later adulthood (Overbeek, Stattin, Vermulst, Ha, \& Engels, 2007). Given the potential long-term impact of early relationships, it is important to understand romantic relationships in emerging adulthood because this is the period in which individuals begin to contemplate committed relationships (Arnett, 2006). Emerging adulthood, sometimes referred to as young adulthood, has typically been defined as a distinct developmental period in industrialized countries that spans roughly 18 to 29 years of age (Arnett, 2000, 2004). Sassler (2010) also called for more research on partnering behaviors across the life course, describing a need for a better understanding of how early relationships may affect relationships in the future.

Emerging adulthood is a particularly important period as developing romantic relationships are viewed as having great uncertainty and potential turbulence because partners are searching for indications that the relationship will continue while they transition toward a more committed relationship (Solomon \& Knobloch, 2004). Two indicators for success are attitudes toward sacrifice for the relationship (Stanley \& Markman, 1992; Whitton, Stanley, \& Markman, 2002; Van Lange, Rusbult, Drigotas, Arriaga, Witcher, \& Cox, 1997) and commitment in the form of dedication to the relationship (see Stanley \& Markman, 1992; Stanley, Markman, \& Whitton, 2002; Stanley, Rhoades, \& Whitton, 2010). Additionally, commitment and attitudes toward sacrificing in romantic relationships have been found to be important correlates of relationship distress, health, and stability (Stanley \& Markman, 1992; Stanley, Whitton, Sadberry, Clements, \& Markman, 2006; Wieselquist, Rusbult, Foster, \& Agnew, 1999). For example, sacrificing in relationships is positively associated with relationship satisfaction and attachment (Ruppel \& Curran, 2012), positive emotions (Kogan et al., 2010), personal well-being and relationship quality (Impett, Gable, \& Peplau, 2005), and commitment (Van Lange, Agnew, Harinck, \& Steemers, 1997). Further, the perception that sacrifice is harmful to the self is negatively association with relationship commitment and couple functioning (Whitton, Stanley, \& Markman, 2007). Because of the potential positive influence of these constructs on relationship functioning, it is important to understand how they develop in relationships. Few researchers, however, have examined the development of these two constructs over time within emerging adult romantic relationships. 
Additionally, although researchers have found support for the relationship between commitment and sacrifice, the direction of this relationship is still unclear. Some past research on the development of commitment has focused on the association of sacrifice (in the forms of willingness to sacrifice, motives to sacrifice, or satisfaction in sacrificing) for a partner on subsequent commitment (e.g., Wieselquist, Rusbult, Foster, \& Agnew, 1999). Yet other researchers have indicated that the reverse may be true, in that early commitment can predict later sacrifice (e.g., Van Lange et al., 1997a).

In line with this contradiction, some researchers allude to a reciprocal relationship, or mutual growth cycle, between the two constructs of commitment and pro-relationship acts, indicating that more commitment is predictive of a greater willingness to sacrifice, which, in turn, promotes more commitment (Wieselquist et al., 1999). Moreover, the mutual growth cycle theorists specifically indicate that the process of interdependence plays a role in facilitating a bidirectional influence between commitment and pro-relationship behaviors (Wieselquist et al., 1999). In the present study, the authors investigate the association between commitment (in the form of dedication) and sacrifice (in the form of satisfaction with sacrifice) to examine how these constructs influence each other given their important association with relationship stability (Stanley et al., 2006).

\section{Building Interdependence}

Interdependence theory (Kelley, 1979; Kelley \& Thibaut, 1978; Thibaut \& Kelley, 1959) posits that the motivation to develop and maintain relationships is a result of the benefits that come from the relationship outweighing its costs combined with poor alternatives (see Rusbult \& Buunk, 1993). Rusbult and colleagues (1983; Agnew, Van Lange, Rusbult, \& Langston, 1998) define commitment as a long-term orientation to the relationship that includes the intent to continue the relationship. This commitment then leads to an increased likelihood that the relationship will persist (Arriaga \& Agnew, 2001). Also drawing on interdependence theory, the investment model further suggests that commitment develops out of changes in dependence over time (Rhoades, Stanley, \& Markman, 2010; Rusbult, 1980; Rusbult, Martz, \& Agnew, 1998). As individuals become increasingly dependent on their relationships, they tend to become more satisfied with the relationship and thus invest more in it (Rusbult, 1980, 1983). As commitment increases, so does interdependence, resulting in partners thinking of themselves as a collective "we" versus an individualistic "I" (Agnew et al., 1998). This interdependence orientation reflects a "transformation of motivation" to a more communal attitude (see Kelley \& Thibaut, 1978) whereby the expected benefits of engaging in relationship maintenance are increased (Agnew et al., 1998; Van Lange et al., 1997b), thus leading to further investment in the relationship. 
Accordingly, although researchers have studied many forms of sacrifice, sacrifice has previously been defined as the tendency to forego self-interest or desired activities for the good of the relationship (Van Lange et al., 1997a, 1997b; Wieselquist et al., 1999). Sacrificing in relationships may be active, such as participating in undesirable activities, or passive, such as forfeiting desirable goals or outcomes (Impett et al., 2005; Van Lange et al., 1997b). In contrast to attitudinal measures such as satisfaction with sacrifice, sacrifice has also been measured by both self-reports (see Ruppel \& Curran, 2012; Whitton et al., 2007) and behavioral measures (Van Lange et al., 1997b), which focus on sacrifices that are actually performed. Previous work on relationship maintenance, however, has indicated that perception of a behavior has a stronger influence on commitment than the actual engagement in the behavior itself (Ogolsky \& Bowers, 2013). Therefore, the present study focused on perceived attitudes of sacrifice, specifically satisfaction with sacrificing for the relationship. Some confusion can occur, however, as sacrifice has been considered both an investment in the relationship (Stanley, 1998) and as a maintenance behavior (Agnew et al., 1998). Clarifying how attitudes toward sacrifice interact with commitment in the form of dedication will inform theory on the developmental trajectories of early romantic relationships.

\section{Which Came First, Commitment or Sacrifice?}

\section{SACRIFICE Builds COMMITMENT}

The documented association between commitment and sacrifice raises the question of temporal precedence. The investment model suggests that feelings of commitment emerge as a consequence of investment (Rusbult, 1980, 1983), and because sacrifice has been considered an investment into the relationship (Whitton et al., 2002; Stanley, 1998; Van Lange et al., 1997b), sacrifice should predict subsequent commitment. In fact, it was suggested that "an act of sacrifice may be experienced as an investment in one's relationship, which in turn may strengthen feelings of commitment" (Van Lange et al., 1997b, p. 1377). Kelley (1979) also theorized that sacrifices may build commitment because, according to interdependence theory for stable relationships to continue, certain prosocial maintenance behaviors, such as sacrificing for the good of the partner and the relationship, should take place (Kelley \& Thibaut, 1978; Rusbult \& Buunk, 1993; Stanley \& Markman, 1992; Van Lange et al., 1997b). For example, empirical research also supports that commitment can be an outcome of relationship maintenance (Canary, Stafford, \& Semic, 2002).

\section{COMMITMENT LEADS TO SACRIFICE}

In contrast to the viewpoint outlined above, many researchers conceptualize relationship maintenance processes, such as attitudes about sacrifice, as a 
consequence of commitment (e.g., Rusbult \& Van Lange, 2003; Van Lange et al., 1997a). For example, dedication, a form of commitment, has been operationalized as the desire to maintain or improve relationship quality for the mutual benefit of the partner. This desire implies a willingness to invest or even a satisfaction with sacrificing for the relationship (Stanley \& Markman, 1992). In support of these ideas, some studies have found that commitment is positively related to subsequent sacrifice (e.g., Stanley et al., 2006; Van Lange et al., 1997b).

\section{A BidireCtional ReLATIONSHIP}

These contradictory definitions and previous findings provide justification to investigate the possibility of a bidirectional relationship between dedication and satisfaction with sacrifice. In fact, according to the mutual growth cycle model (Wieselquist et al., 1999), dependence can promote commitment that can then promote trust, through acts such as accommodation and sacrificing for a partner. Specifically, researchers theorized that when partners observe each other's pro-relationship behaviors, their trust and dependence increase, leading to increased commitment (Wieselquist et al., 1999). Therefore, commitment can lead to pro-relationship behaviors. These pro-relationship behaviors can, in turn, build trust in the future of the relationship and thus foster more commitment to the relationship. In other words, the theory proposes a reciprocal model in which commitment and pro-social behaviors establish a mutually enhancing cycle. In addition, there is previous support for a bidirectional relationship in similar variables, as commitment and relationship maintenance have been shown to reinforce each other in same-sex couples (Ogolsky, 2009).

To provide clarity on the directionality of this relational investment, as well as maintenance process, we test the reciprocal pattern of an individual's satisfaction with sacrifice and their dedication to the relationship. We seek to test the direction of effects in emerging adulthood, as this is when individuals are typically contemplating long-term, committed relationships (Arnett, 2006; Fincham, Stanley, \& Rhoades, 2011). Using three waves of data, we test three hypotheses:

H1: Time 1 satisfaction with sacrifice will be positively associated with dedication at Time 2 and Time 2 satisfaction with sacrifice will be positively associated with dedication at Time 3.

H2: Time 1 dedication will be positively associated with satisfaction with sacrifice at Time 2 and Time 2 dedication will be positively associated with satisfaction with sacrifice at Time 3.

H3: To further support the constructs' reciprocal nature, dedication at Time 1 will be positively associated with dedication at Time 3, through the partial mediation of satisfaction with sacrifice at Time 2. Similarly, satisfaction with sacrifice at Time 1 will be positively associated with satisfaction with sacrifice at Time 3 through the partial mediation of dedication at Time 2. 


\section{Relationship Length and Instability in the Form of Cycling}

Interdependence theory suggests that an increased sense of interdependence plays a key role in facilitating maintenance behaviors that protect against instability (see Agnew et al., 1998; Rusbult \& Buunk, 1993). It has been estimated, however, that about $30 \%$ to $40 \%$ of young adult dating partners have experienced at least one breakup and reconciliation ("on-again/ off-again" status) with their current partner (termed "cycling"; Dailey, Pfiester, Jin, Beck, \& Clark, 2009; Vennum, Lindstrom, Monk, \& Adams, 2014). Because that dedication has been shown to predict relationship stability (Rhoades, Stanley, \& Markman, 2010) and cycling has been shown to influence levels of commitment and relationship maintenance (Dailey, Hampel, \& Roberts, 2010), it is possible that there is a shift in the development of interdependence due to the lack of stability in cyclical relationships. Further, cyclical partners report relationships of longer duration than noncyclical partners (Dailey et al., 2009; Halpern-Meekin et al., 2013) and the association between commitment and relational maintenance has been found to change as relationship duration increases (Ogolsky, 2009). Accordingly, cycling and relationship length will be assessed as controls and moderators in determining the final model.

\section{METHODS}

\section{Procedure}

Data were drawn from a larger study of young adult romantic relationships collected at a large southeastern university. Participants were enrolled in an introductory family studies course that was an option for meeting liberal studies requirements, so the majority of colleges and majors on campus were represented (Fincham, Cui, Braithwaite, \& Pasley, 2008). Students were offered several options to earn class credit, one of which was to participate in the larger study by completing an online survey. Students who chose to participate were emailed a secure survey link during the 2nd (T1), 8th (T2), and 15th (T3) weeks of the semester. Approval from the institutional review board was obtained before any data collection at the institution where the original data were collected as well as from the current institution where the secondary data analysis was conducted.

\section{Sample}

The sample comprised 246 emerging adults (18-29 years of age) who indicated they were in exclusive dating (nonmarried) relationships. The majority of the sample reported being heterosexual (97.2\%), and $10.7 \%$ indicated they were currently living with their romantic partner. The mean age of 
the participants was 19.5 (standard deviation $[S D]=1.4$ ) at the start of the study and $79 \%$ indicated their sex as female. From an initial sample of 357 in exclusive dating relationships, participants were dropped from the study if they had broken up with their partner during the course of the semester $(n=78)$ or if they did not participate at all three time points $(n=33)$. Although Mplus can handle missing data, these participants were excluded because it was not known if they renewed their relationship with the same partner over the course of the semester. Compared with the overall sample, participants who did not respond at all three time points were more likely to be male and African American or Latino.

Nearly $31 \%(n=77)$ of those in exclusive relationships indicated their relationship was cyclical (they had broken up and renewed their current relationship at least once). The mean length of relationships was around 18.5 months $(S D=17.16)$. About $72 \%$ indicated their ethnicity as White, 13\% Latino, 7\% African American, 2\% Native American or Asian, and the remaining indicated they were mixed race or "Other."

\section{Measures}

\section{DEDICATION}

Dedication to the relationship was measured using a subscale derived from the Commitment Inventory (Stanley \& Markman, 1992). We used four items that had participants report their level of agreement on a five-point scale ranging from strongly disagree (1) to strongly agree (5) (see Stanley, Markman, \& Whitton, 2002; Stanley, Whitton, \& Markman, 2004). Sample items were "I like to think of my partner and me more in terms of 'us' and 'we' than 'me' and 'him/her'," and "I want this relationship to stay strong no matter what rough times we may encounter." Responses were coded so higher scores reflect greater dedication. A confirmatory factor analysis (CFA) with items used as indicators was run to test construct validity and values were indicative of good loading for all variables (all were above the .6 recommendation; see Kline, 2011). Coefficient alphas were all above .80 (see Table 1 for specific alphas for each time point).

\section{SATISFACTION WITH SACRIFICE}

Also part of the Commitment Inventory (Stanley \& Markman, 1992), the satisfaction with sacrifice subscale assesses the attitude an individual has toward sacrifice and its level of benefit to the relationship. Participants indicated their level of agreement with six items on a scale from strongly disagree (1) to strongly agree (7). For example, "It can be personally fulfilling to give up something for my partner," "I am not the kind of person that finds satisfaction in putting aside my interests for the sake of my relationship with my partner," and "giving something up for my partner is frequently not 
TABLE 1 Descriptive Statistics, Alphas, and Correlations for Study Variables ( $n=246)$

\begin{tabular}{lccccccr}
\hline & 1 & 2 & 3 & 4 & 5 & 6 & \multicolumn{1}{c}{7} \\
\hline 1. T1 Dedication & - & & & & & & \\
2. T2 Dedication & $.71^{* * *}$ & - & & & & & \\
3. T3 Dedication & $.69^{* * *}$ & $.72^{* * *}$ & - & & & & \\
4. T1 Sat w/ Sac & $.58^{* * *}$ & $.47^{* * *}$ & $.52^{* * *}$ & - & & & \\
5. T2 Sat w/ Sac & $.28^{*}$ & $.49^{* * *}$ & $.51^{* * *}$ & $.61^{* * *}$ & - & & \\
6. T3 Sat w/ Sac & $.43^{* * *}$ & $.43^{* * *}$ & $.62^{* * *}$ & $.64^{* * *}$ & $.54^{* * *}$ & - & \\
7. Rel. length & .19 & .23 & .19 & .07 & .05 & .23 & - \\
$\alpha$ & .81 & .80 & .80 & .89 & .86 & .87 & - \\
Mean & 18.07 & 18.27 & 18.01 & 33.16 & 32.44 & 33.40 & 18.50 \\
SD & 3.03 & 2.80 & 3.00 & 6.69 & 6.20 & 6.54 & 17.16 \\
Min & 6.00 & 6.00 & 6.00 & 6.00 & 16.00 & 6.00 & 1.00 \\
Max & 22.00 & 22.00 & 22.00 & 42.00 & 42.00 & 42.00 & 170.00 \\
\hline
\end{tabular}

Sat w/ Sac, satisfaction with sacrifice; Rel. length, length of the relationship. ${ }^{*} p<.05,{ }^{* *} p<.01,{ }^{* * *} p<.001$.

worth the trouble." Items were recoded and computed so that higher scores indicate greater satisfaction with sacrifice. A CFA was conducted using the items as indicators and resulted in loadings above .6. Coefficient alphas were all above .86 (see Table 1).

\section{RELATIONSHIP LENGTH}

The duration of the relationship was reported as the number of years and months they had been with their partner, which was converted into total number of months together.

\section{RELATIONSHIP CYCLING}

A history of cycling was reported at T1 by indicating whether their current relationship was one in which they had "broken up and gotten back together at least once." Partners who indicated yes were included in the cyclical group and those who answered no were designated as noncyclical.

SEX

Sex was initially used as a control variable $(0=$ female, $1=$ male $)$; however, because it was not significantly related to dedication and satisfaction with sacrifice, it was removed from the final model.

\section{Analytic Strategy}

After preliminary analysis of correlations, we assessed the fit of a CFA to verify dedication and satisfaction with sacrifice were distinct constructs. We then determined our base path model, controlling for cycling and 
relationship length. With our base path model established, we tested whether cycling and relationship length moderated the association between dedication and satisfaction with sacrifice.

Analyses were run in Mplus 6.11 (Muthén \& Muthén, 1998-2011), and missing data were handled with full information maximum likelihood, because it is considered one of the least biased methods (see Acock, 2005; Allison, 2003). Although most of the data were distributed normally, kurtosis values for relationship length were outside the recommended range (Byrne, 2012), so maximum likelihood robust (MLR) estimation was used for the cross-lagged panel analysis. MLR is recommended to account for non-normality within the data to give less biased parameter estimates (Yuan \& Bentler, 2000). Because bootstrapping is not possible when using MLR, Sobel's test for mediation was used to calculate indirect effects (see Preacher $\&$ Hayes, 2008). Additionally, because the $\chi^{2}$ test is influenced by sample size and may result in lack of significance even when the model is minimally mispecified (Marsh, Hau, \& Wen, 2004), the root mean square error approximation (RMSEA), comparative fit index (CFI), and standardized root mean square residual (SRMR) were used to examine overall model-data fit. Values smaller than .08 for RMSEA and .10 for SRMR, as well as values greater than .95 for CFI suggest acceptable model fit (see Hu \& Bentler, 1999; Kline, 2011; McDonald \& Ho, 2002).

\section{RESULTS}

\section{Descriptive Statistics and Correlations}

Table 1 provides the correlations for the main variables of interest as well as the alphas for each scale by time point. As expected, dedication was positively correlated with itself at all time points. The same was true for satisfaction with sacrifice. Satisfaction with sacrifice and dedication were also positively correlated at each time point. Because cycling was a dichotomous variable, a point biserial correlation was conducted and found that it was positively correlated with the length of the relationship $\left(r_{\mathrm{pb}}=.24, p>.001\right)$, as those with a history of cycling reported relationships of longer duration. Means, ranges, and SDs are also listed in Table 1. The average score for dedication at each wave was high but comparable with those reported in other samples (e.g., 18.27 for T2 dedication in our sample, compared with 18.57 for male noncohabitors' mean dedication level; Stanley et al., 2004). Participants were moderately high on satisfaction with sacrifice on average. There was also more variability in satisfaction with sacrifice than with dedication.

\section{Confirmatory Factor Analyses}

Although the constructs of dedication and satisfaction with sacrifice are conceptually different, they are related. Therefore, a CFA with dedication 
and satisfaction with sacrifice as correlated latent factors and scale items as indicators was conducted to ensure they were distinct constructs. This model was a good fit to the data $\left(\chi^{2}[20]=23.79, p<.05\right.$; RMSEA $=.03[90 \%$ confidence interval, .00-.06], CFI $=1.0$, SRMR $=.02$ ). All items loaded above .6 on their respective factors with no cross-loadings between the two latent constructs. The covariance between dedication and satisfaction with sacrifice at T1 was $r=.54(p<.001)$, indicating that the constructs are related but distinct. Accordingly, the next step was to test the cross-lagged panel model.

\section{Cross-Lagged Panel Analysis}

Given adequate fit of the two-factor CFA, a cross-lagged panel analysis was conducted to test the reciprocal relationship between dedication and satisfaction with sacrificing for a romantic partner, controlling for relationship length and cycling. Initially the model was tested with all paths freely estimated; however, constraining corresponding paths to be equivalent (e.g., the parallel cross paths from T1 satisfaction with sacrifice to T2 dedication [labeled "a"] and T2 satisfaction with sacrifice to T3 dedication [also labeled "a"] were constrained to be equivalent; see Figure 1 with constrained paths labeled) increased parsimony and did not significantly decrease the fit of the model based on the results of a Satorra-Bentler scaled $\chi^{2}$ difference test (see Kline, 2011 for common practices of constraining; see Cui, Donnellan, \& Conger, 2007 for an example of constraints in cross-lagged panel analyses). The resulting model was a good fit to the data: $\chi^{2}(12)=14.70, p>.05$; RMSEA $=.03$ (90\% confidence interval, .000-.078), CFI $=1.0$, and SRMR $=.04$.

With the base path model established, we next examined whether relationship length or a history of cycling changed the direction or strength of the relationship between dedication and satisfaction with sacrifice. We consecutively constrained the paired parameters outlined in Figure 1 to be equivalent across groups (cyclical versus noncyclical and short versus long relationships) and used Satorra-Bentler scaled $\chi^{2}$ difference tests to

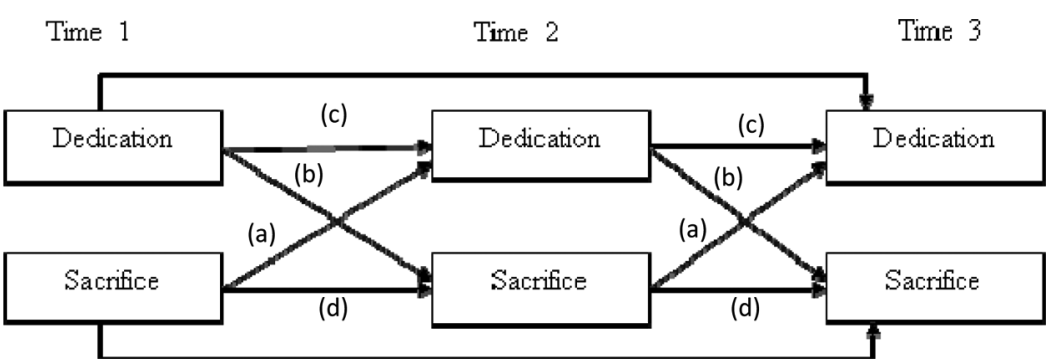

FIGURE 1 Cross-lagged panel analysis for dedication and satisfaction with sacrifice. Dedication and satisfaction with sacrifice at T2 are correlated together, as well as T3. Constrained paths are labeled with corresponding letters. 


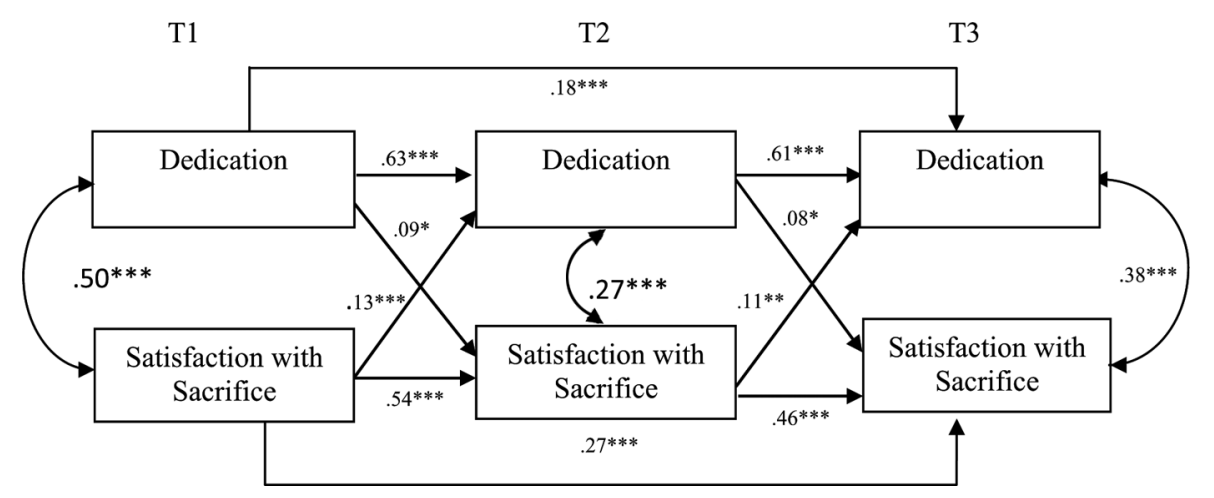

FIGURE 2 Standardized path coefficients for the combined bidirectional model. The control variables cycling and relationship length are not shown. ${ }^{*} p<.05,{ }^{* *} p<.01,{ }^{* * *} p<.001$.

determine whether each constraint significantly decreased the fit of the model. Constraining all pairs of path coefficients to be equivalent across groups did not fit the data significantly worse than allowing separate models to be freely estimated for each group, indicating that neither relationship length nor a history of cycling moderated the relationship between dedication and satisfaction with sacrifice in this sample. Thus, we present the results of our final model including all participants in the same group with cycling and relationship length as controls (Figure 2).

\section{DIRECT EFFECTS}

The results show support for a direct association between satisfaction with sacrifice at T1 and dedication at T2 $(\beta=.13, p<.001)$, as well as satisfaction with sacrifice at T2 to dedication at T3 $(\beta=.11, p<.01)$, holding other variables constant. Conversely, there was a direct association between dedication at T1 to satisfaction with sacrifice at T2 $(\beta=.09, p<.05)$ and dedication at T2 and satisfaction with sacrifice at T3 $(\beta=.08, p<.05)$. There was also a direct association between satisfaction with sacrifice at T1 and satisfaction with sacrifice at T3 $(\beta=.27, p<.001)$, along with a direct association between dedication at T1 and dedication at T3 $(\beta=.18, p<.001)$. See Figure 2 for direct effects. We also found a significant effect for relationship length, as it was associated with T1 dedication $(\beta=.24, p<.001)$. In addition, cycling was negatively associated with T3 dedication $(\beta=-.09, p<.05)$.

\section{INDIRECT EFFECTS}

Further, the indirect paths, reported in Table 2 , from dedication at T1 to dedication at T3 were significant through satisfaction with sacrifice at T2 $(\beta=.01$, $p<.05)$ and dedication at T2 $(\beta=.40, p<.001)$, indicating partial mediation. 
TABLE 2 Mediating Effects for the Cross-Lagged Panel Analysis for Dedication and Satisfaction with Sacrifice

\begin{tabular}{|c|c|c|c|}
\hline Predictor & Mediator & Outcome & $\beta$ \\
\hline T1 Dedication $\rightarrow$ & T2 Dedication $\rightarrow$ & T3 Dedication & $.40^{* * *}$ \\
\hline T1 Dedication $\rightarrow$ & T2 Sat w/ Sac $\rightarrow$ & T3 Dedication & $.01^{*}$ \\
\hline T1 Sat w/ Sac $\rightarrow$ & T2 Dedication $\rightarrow$ & T3 Dedication & $.08^{* * *}$ \\
\hline T1 Sat w/ Sac $\rightarrow$ & T2 Sat w/ Sac $\rightarrow$ & T3 Dedication & $.06^{* *}$ \\
\hline T1 Sat w/ Sac $\rightarrow$ & T2 Dedication $\rightarrow$ & T3 Sat w/ Sac & $.01^{*}$ \\
\hline T1 Sat w/ Sac $\rightarrow$ & T2 Sat w/ Sac $\rightarrow$ & T3 Sat w/ Sac & $.25^{* * *}$ \\
\hline T1 Dedication $\rightarrow$ & T2 Dedication $\rightarrow$ & T3 Sat w/ Sac & $.05^{*}$ \\
\hline T1 Dedication $\rightarrow$ & T2 Sat w/ Sac $\rightarrow$ & T3 Sat w/ Sac & $.04^{*}$ \\
\hline
\end{tabular}

Indirect paths tested with Sobel's test of mediation. Sat w/Sac $=$ satisfaction with sacrifice.

${ }^{*} p<.05,{ }^{* *} p<.01,{ }^{* * *} p<.001$.

This was also true for the paths from satisfaction with sacrifice at T1 to dedication at $\mathrm{T} 3$ through the mediation of dedication at $\mathrm{T} 2(\beta=.08$, $p<.001)$ and satisfaction with sacrifice at $\mathrm{T} 2(\beta=.06, p<.01)$. The indirect paths from satisfaction with sacrifice at T1 to satisfaction with sacrifice at T3 were significant through the mediation of satisfaction with sacrifice at $\mathrm{T} 2(\beta=.25, p<.001)$ and dedication at T2 $(\beta=.01, p<.05)$. Additionally, the indirect paths from dedication at T1 and satisfaction with sacrifice at T3 were significant through the mediation of satisfaction with sacrifice at T2 $(\beta=.04, p<.05)$ and dedication at T2 $(\beta=.05, p<.05)$.

\section{DISCUSSION}

In the current study, we found support for our first hypothesis that satisfaction with sacrifice can build subsequent dedication to the relationship. Conversely, we also found support for the reverse, in that dedication was predictive of satisfaction with sacrifice (hypothesis 2). In support of the third hypothesis, there was evidence of a reciprocal pattern evidenced by partial mediation in our sample. Therefore, we help clarify some conflicting findings in the literature by providing support for the bidirectional nature of the positive associations between dedication and satisfaction with sacrifice for emerging adults. Additionally, although Stanley and Markman (1992) include satisfaction with sacrifice as a subscale of commitment, according to the results of the CFA with both latent constructs, dedication and satisfaction with sacrifice can be considered distinct.

Because of our finding of a bidirectional relationship, we support the theoretical contributions of the mutual growth cycle, which suggests that a willingness to sacrifice and commitment can promote an enhancing cycle (Wieselquist et al., 1999). Moreover, the mutual growth cycle indicates that commitment and pro-social acts build on each other by way of an individual gaining trust in the benevolent intentions of a partner, which can increase 
willingness for the individual to be dependent on their partner. This increased dependence can then facilitate commitment and the odds of enacting reciprocal, pro-social acts (Wieselquist et al., 1999).

From the perspective of interdependence theory, it could be that partners who feel committed to the relationship, as they have intent to continue the relationship, feel more comfortable investing in its future. Conversely, this attitude toward investing or sacrificing also seems to facilitate a greater sense of commitment to the relationship (Kelley, 1979; Kelley \& Thibaut, 1978; Rusbult \& Buunk, 1993). This is likely due to an interdependent mental process of going from an "I" to a "we" that helps facilitate communal attitudes (Agnew et al., 1998). Therefore, these partners seem to be committed because they are satisfied with sacrificing for the preservation of their relationship and are satisfied with sacrificing because they are committed to the continuation of their relationship. Similarly, social exchange principles, such as the "sunk cost effect" (see Coleman, 2009), would suggest that someone would be more committed if they believed they had put more effort or sacrifice into the relationship ("I have put so much into this and given so much, I should see it through"; see also, Kelley, 1979; Kelley \& Thibaut, 1978; Rusbult \& Buunk, 1993). Based on our findings, we argue that this bidirectional relationship is universal across relationship types, as a similar process was discussed for married couples in a different geographic region and who were slightly older (Wieselquist et al., 1999), as well as with same-sex couples (Ogolsky, 2009).

Interestingly, we also found two significant effects of our control variables. We found a mean difference between cyclical and noncyclical groups in their reports of dedication at Time 3. Those with a history of cycling reported lower levels of dedication, which is consistent with previous research (see Dailey et al., 2009). Despite findings in previous research that partners with a history of cycling report decreased relationship maintenance behaviors (see Dailey, Hampel, \& Roberts, 2010), we did not find significant mean differences in satisfaction with sacrifice in the present study. It may be a function of the developmental period, as emerging adulthood is a time for exploration of identity and relationships (Arnett, 2000, 2006). Therefore, although dedication to these relationships may change, emerging adults may still find personal fulfillment in accommodating their partners as a function of clarifying their identity or role as a partner. Additionally, although cycling was predictive of a lower level of dedication, cycling did not change the directionality of the association between the constructs through moderation. It may be that though cycling influences commitment, it does not change the positive association between dedication and satisfaction with sacrifice.

Relationship length was positively associated with dedication at Time 1, although it did not moderate the relationship between the dedication and satisfaction with sacrifice. Not finding moderation could be attributed to the fact that emerging adults have not been in relationships for long, as they 
are just entering the stage of seeking longer term commitments (see Arnett, 2006) and therefore because dedication and satisfaction with sacrifice mutually develop their association would remain similar over the early phases of the relationship. Clarifying this pattern for early relationships is important because emerging adults have shorter relationships and research has indicated a potential for turbulence, or instability, during the transition to a more exclusive commitment (see Solomon \& Knobloch, 2004).

Because of this reciprocal effect, it may be difficult to gain insight into which occurs first. It was suggested that relationship maintenance predicting commitment may be more characteristic of early stages of a relationship, whereas commitment predicting subsequent maintenance may be more characteristic of those that have been in a relationship longer (Ogolsky, 2009). Accordingly, because we studied emerging adults who are early in their relationships, the former explanation of maintenance predicting commitment may be more characteristic.

\section{Implications}

The results suggest that sacrifice may be conceptualized as both an investment, when it builds commitment, and a relationship maintenance behavior, when it sustains existing commitment. This would imply that there is an increased benefit to committing to a relationship and having a positive attitude toward sacrifice, as they seem to be bidirectional in nature as was implied by the mutual growth cycle (Wieselquist et al., 1999).

Although it does seem beneficial to sacrifice for the partner, some researchers indicated that it can be harmful and even lead to depression (Whitton et al., 2007). These authors reported that it is not the sacrifice itself but the way in which the individual views that sacrifice (e.g., satisfaction with sacrifice versus feeling that the individual gives up more than their partner). In fact, better relationship functioning was found in both men and women who viewed sacrifice as less harmful to themselves (Whitton et al., 2007). Therefore, it is likely that although an interdependent orientation and sacrifice can be good for the relationship, there may be a point at which there is a plateau in terms of increasing commitment or even a point of decrease if a partner is under benefiting and giving too much. Accordingly, researchers and clinicians should focus on healthy patterns that promote this reciprocal or reinforcing bidirectional process both with the constructs individually ("I am more committed so I am willing to sacrifice more") and as an interdependent reciprocal process among partners ("my partner has given-up so much to show their commitment, I want to reciprocate").

\section{Limitations and Future Directions}

The findings of this study need to be viewed in the context of its limitations. First, this study did not include dyadic data; therefore, true interdependence 
between partners was not measured. Instead, we looked at the bidirectional and reciprocal process within the individual only and not as a "couple process." Future research should incorporate responses from both partners. This use of dyadic data will provide more insight into dyadic processes that may govern the operation of these variables and how the process may be operate reciprocally between partners in the dyad (e.g., partner A sacrifice predicts later partner B dedication that, in turn, predicts partner A satisfaction with sacrifice at a later point in time).

Second, the collection of the data was over a relatively short time (15 weeks) and may not fully capture the process as it occurs over longer periods of time for emerging adults. Moreover, all data were self-report. It would be beneficial for future research to have data across more time points and across a longer period of time, as well as data that reflect the use of multiple sources and methods (e.g., self-report, partner report, and observation to capture actual sacrificing behaviors). Additionally, collecting data in a larger sample and with more variation in relationship length may allow for better assessment of potential moderating effects.

Third, the data used in the present study did not capture a true starting point for the couples or "day 1" of the relationship to fully articulate which construct would occur first in the development of the relationship. Thus, we did not find evidence that one particular variable "comes first" but instead that it can be a bidirectional or reciprocal process in ongoing relationships. Future research should investigate relationships closer to their initiation to capture their "starting point," either through recollection or ideally locating couples willing to participate early in their relationship. Future research should also investigate cycling in relationships during the semester, instead of just a history of cycling in the current relationship. In addition, there was limited diversity in the sample. Most of the sample identified themselves as White, female, and heterosexual, thereby possibly limiting the generalizability to other noncollege emerging adults from minority groups. Our sample does approach the demographics for the overall college population as women have exceeded the number of men in higher education. This is mostly due to a $62 \%$ increase in female attendance from 2000 to 2010 . In addition, though the number of Minority students in postbaccalaureate programs is rising, the majority still identifies as White (U.S. Department of Education, 2012).

\section{Conclusion}

The finding of a reciprocal relationship between dedication and satisfaction with sacrifice in exclusive dating relationships among emerging adults supports interdependence theory. We suggest that changing an individual focus to an interdependent orientation (shifting focus to the good of the relationship instead of self-interest) is the mechanism that likely intertwines commitment with satisfaction with sacrifice. This intertwining process is 
consistent with previous literature (Wieselquist et al., 1999). Therefore, it could be that those who put aside self-interest may be more committed because they have a more positive attitude toward sacrifice and have a positive attitude toward sacrifice because they are committed. We found this effect even when variables of interest at all time points, a history of instability and relationship length were included in the model.

\section{ACKNOWLEDGMENTS}

This article is part of a project completed as a thesis with collaboration from a thesis committee consisting of chair Amber Vennum, Ph.D., and members Jared Anderson, Ph.D., Walter R. Schumm, Ph.D., and Jared Durtschi, Ph.D. The present study used data from a larger study on young adult romantic relationships collected by the Family Institute at The Florida State University supported in part by a grant from the U.S. Department of Health and Human Services (no. 90FE0022) awarded to Dr. Frank D. Fincham.

\section{REFERENCES}

Acock, A. (2005). Working with missing values. Journal of Marriage and Family, 67, 1012-1028.

Agnew, C. R., Van Lange, P. A. M., Rusbult, C. E., \& Langston, C. A. (1998). Cognitive interdependence: Commitment and the mental representation of close relationships. Journal of Personality and Social Psychology, 74, 939-954.

Allison, P. D. (2003). Missing data techniques for structural equation modeling. Journal of Abnormal Psychology, 112, 545-557.

Arnett, J. J. (2000). Emerging adulthood: A theory of development from the late teens through the twenties. American Psychologist, 55, 469-480.

Arnett, J. J. (2004). Emerging adulthood: The winding road from the late teens through the twenties. New York: Oxford University Press.

Arnett, J. J. (2006). Emerging adulthood: Understanding the new way of coming of age. In J. J. Arnett \& J. L. Tanner (Eds.), Emerging adults in America: Coming of age in the 21st century (pp. 3-20). Washington, DC: American Psychological Association Press.

Arriaga, X. B., \& Agnew, C. R. (2001). Being committed: Affective, cognitive, and conative components of relationship commitment. Personality and Social Psychology Bulletin, 27, 1190-1203.

Byrne, B. M. (2012). Structural equation modeling with Mplus: Basic concepts, applications, and programming. New York, NY: Routledge.

Canary, D., Stafford, L., \& Semic, B. (2002). A panel study of the associations between maintenance strategies and relational characteristics. Journal of Marriage and the Family, 64, 395-406.

Coleman, M. D. (2009). Sunk cost and commitment to dates arranged online. Current Psychology, 28, 45-54. 
Cui, M., Donnellan, M. B., \& Conger, R. D. (2007). Reciprocal influences between parents' marital problems and adolescent internalizing and externalizing behavior. Developmental Psychology, 43, 1544-1552.

Dailey, R., Hampel, A., \& Roberts, J. (2010). Relational maintenance in on/off relationships: An assessment of how relational maintenance, uncertainty, and commitment vary by relationship type and status. Communication Monographs, 77, 75-101.

Dailey, R. M., Pfiester, A., Jin, B., Beck, G., \& Clark, G. (2009). On-again/off-again dating relationships: How are they different from other dating relationships? Personal Relationships, 16, 23-47.

Donnellan, M. B., Larsen-Rife, D., \& Conger, R. D. (2005). Personality, family history, and competence in early adult romantic relationships. Journal of Personality and Social Psychology, 88, 562-576.

Fincham, F. D., Cui, M., Braithwaite, S. R., \& Pasley, K. (2008). Attitudes towards intimate partner violence in dating relationships. Psychological Assessment, 20, 260-269.

Fincham, F. D., Stanley, S. M., \& Rhoades, G. (2011). Relationship education in emerging adulthood: Problems and prospects. In F. D. Fincham \& M. Cui (Eds.), Romantic relationships in emerging adulthood (pp. 293-316). Cambridge, UK: Cambridge University Press.

Halpern-Meekin, S., Manning, W. D., Giordano, P. C., \& Longmore, M. A. (2013). Relationship churning in emerging adulthood on/off relationships and sex with an ex. Journal of Adolescent Research, 28, 166-188.

Hu, L., \& Bentler, P. M. (1999). Cutoff criteria for fit indexes in covariance structure analysis: Conventional criteria versus new alternatives. Structural Equation Modeling, 6, 1-55.

Impett, E. A., Gable, S. L., \& Peplau, L. A. (2005). Giving up and giving in: The cost and benefits of daily sacrifice in intimate relationships. Journal of Personality and Social Psychology, 89, 327-344.

Kelley, H. H. (1979). Personal relationships: Their structures and processes. Hillsdale, NJ: Erlbaum.

Kelley, H. H., \& Thibaut, J. W. (1978). Interpersonal relations: A theory of interdependence. New York, NY: Wiley.

Kline, R. B. (2011). Principles and practice of structural equation modeling (3rd ed.). New York, NY: Guilford Press.

Kogan, A., Impett, E. A., Oveis, C., Hui, B., Gordon, A. M., \& Keltner, D. K. (2010). When giving feels good: The intrinsic benefits of sacrifice in romantic relationships for the communally motivated. Psychological Science, 21, 1918-1924.

Marsh, H. W., Hau, K.-T., \& Wen, Z. (2004). In search of golden rules: comment on hypothesis testing approaches to setting cutoff values for fit indexes and dangers in overgeneralizing $\mathrm{Hu}$ and Bentler's (1999) findings. Structural Equation Modeling, 11, 320-341.

McDonald, R. P., \& Ho, M.-H. R. (2002). Principles and practice in reporting structural equation analyses. Psychological Methods, 7, 64-82. doi: 10.1037/1082-989X. 7.1.64

Muthén, L. K., \& Muthén, B. O. (1998-2011). Mplus user's guide (6th ed.). Los Angeles, CA: Muthén \& Muthén. 
Ogolsky, B. G. (2009). Deconstructing the association between relationship maintenance and commitment: Testing two competing models. Personal Relationships, 16, 99-115. doi: 10.1111/j.1475-6811.2009.01212.x

Ogolsky, B. G., \& Bowers, J. R. (2013). A meta-analytic review of relationship maintenance and its correlates. Journal of Social and Personal Relationships, 30, 343-367. doi: 10.1177/0265407512463338

Overbeek, G., Stattin, H., Vermulst, A., Ha, T., \& Engels, R. C. M. E. (2007). Parent-child relationships, partner relationships, and emotional adjustment: A birth-to-maturity prospective study. Developmental Psychology, 43, 429-437.

Preacher, K. J., \& Hayes, A. F. (2008). Asymptotic and resampling strategies for assessing and comparing indirect effects in multiple mediator models. Behavior Research Methods, 40, 879-891.

Rhoades, G. K., Stanley, S. M., \& Markman, H. J. (2010). Should I stay or should I go? Predicting dating relationship stability from four aspects of commitment. Journal of Family Psychology, 24, 543-550.

Ruppel, E. K., \& Curran, M. A. (2012). Relational sacrifices in romantic relationships: Satisfaction and the moderating role of attachment. Journal of Social and Personal Relationships, 29, 508-529.

Rusbult, C. E. (1980). Commitment and satisfaction in romantic associations: A test of the investment model. Journal of Experimental Social Psychology, 16, 172-186.

Rusbult, C. E. (1983). A longitudinal test of the investment model: The development (and deterioration) of satisfaction and commitment in heterosexual involvements. Journal of Personality and Social Psychology, 45, 101-117.

Rusbult, C. E., \& Buunk, B. P. (1993). Commitment processes in close relationships: An interdependence analysis. Journal of Social and Personal Relationships, 10, 175-204.

Rusbult, C. E., Martz, J. M., \& Agnew, C. R. (1998). The investment model scale: Measuring commitment level, satisfaction level, quality of alternatives, and investment size. Personal Relationships, 5, 357-391.

Sassler, S. (2010). Partnering across the lifecourse: Sex, relationships, and mate selection. Journal of Marriage and Family, 72, 557-575.

Satorra, A., \& Bentler, P. M. (2001). A scaled difference chi-square test statistic for moment structure analysis. Psychometrika, 66, 507-514.

Solomon, D. H., \& Knobloch, L. K. (2004). A model of relational turbulence: The role of intimacy, relational uncertainty, and interference from partners in appraisals of irritations. Journal of Social and Personal Relationships, 21, 795-816.

Stanley, S. (1998). The heart of commitment: Compelling research that reveals the secrets of a lifelong, intimate marriage. Nashville, TN: Thomas Nelson.

Stanley, S. M., \& Markman, H. J. (1992). Assessing commitment in personal relationships. Journal of Marriage and Family, 54, 595-608.

Stanley, S. M., Markman, H. J., \& Whitton, S. W. (2002). Communication, conflict, and commitment: Insights on the foundations of relationship success from a national survey. Family process, 41, 659-675.

Stanley, S. M., Rhoades, G. K., \& Markman, H. J. (2006). Sliding versus deciding: Inertia and the premarital cohabitation effect. Family Relations, 55, 499-509.

Stanley, S. M., Rhoades, G. K., \& Whitton, S. W. (2010). Commitment: Functions, formation, and the securing of romantic attachment. Journal of Family Theory and Review, 2, 243-257. 
Stanley, S. M., Whitton, S. W., \& Markman, H. J. (2004). Maybe I do: Interpersonal commitment and premarital or nonmarital cohabitation. Journal of Family Issues, 25, 496-519.

Stanley, S. M., Whitton, S. W., Sadberry, S. L., Clements, M. L., \& Markman, H. J. (2006). Sacrifice as a predictor of marital outcomes. Family Process, 45, 289-303.

Thibaut, J. W., \& Kelley, H. H. (1959). The social psychology of groups. Oxford, UK: John Wiley.

U.S. Department of Education, National Center for Education Statistics. (2012). Digest of Education Statistics, 2011 (NCES 2012-001). Retrieved from http://nces. ed.gov/fastfacts/display.asp?.id=98

Van Lange, P. A. M., Agnew, C. R., Harinck, F., \& Steemers, G. E. M. (1997a). From game theory to real life: How social value orientation affects willingness to sacrifice in ongoing close relationships. Journal of Personality and Social Psychology, 73, 1330-1344.

Van Lange, P. A. M., Rusbult, C. E., Drigotas, S. M., Arriaga, X. B., Witcher, B. S., \& Cox, C. L. (1997b). Willingness to sacrifice in close relationships. Journal of Personality and Social Psychology, 72, 1373-1395.

Vennum, A., Lindstrom, R., Monk, J. K., \& Adams, R. (2014). "It's complicated": The continuity and correlates of cycling in cohabiting and marital relationships. Journal of Social and Personal Relationships, 31, 410-430. doi: 10.1177/ 0265407513501987

Whitton, S. W., Stanley, S. M., \& Markman, H. J. (2002). Sacrifice in romantic relationships: An exploration of relevant research and theory. In H. T. Reiss, M. A. Fitzpatrick, \& A. L. Vangelisti (Eds.), Stability and change in relationship behavior across the lifespan (pp. 156-181). Cambridge, UK: Cambridge University Press.

Whitton, S. W., Stanley, S. M., \& Markman, H. J. (2007). If I help my partner, will it hurt me? Perceptions of sacrifice in romantic relationships. Journal of Social and Clinical Psychology, 26, 64-92.

Wieselquist, J., Rusbult, C. E., Foster, C. A., \& Agnew, C. R. (1999). Commitment, pro-relationship behavior, and trust in close relationships. Journal of Personality and Social Psychology, 77, 942-966.

Yuan, K. H., \& Bentler, P. M. (2000). Three likelihood-based methods for mean and covariance structure analysis with nonnormal missing data. Sociological Methodology, 30, 165-200. 